\title{
MUJERES Y MÚSICA. OBSTÁCULOS VENCIDOS Y CAMINOS POR RECORRER
}

\author{
WOMEN AND MUSIC. OVERCOMING OBSTACLES AND WAYS TO GO
}

\author{
Sandra Soler Campo \\ Universitat Rovira i Virgili
}

\section{RESUMEN}

La historia de las mujeres, se ha centrado fundamentalmente en hacer visible lo que se había ocultado durante años, dando voz a dicho silencio. Así también, ha sido de suma importancia la atención dada a las manifestaciones que la cultura patriarcal ignoró y no reconsideró. La tendencia hasta los años 80 del pasado siglo XX en musicología, se ha basado fundamentalmente en la recogida y acumulación de datos. El hecho que la incorporación del feminismo a la musicología haya sido considerablemente tardía, ha comportado consecuentemente una falta de tradición, una carencia de estudios en los cuales se refleje el gran número de músicas con talento, que fueron marginadas en su época. El hecho que los estudios musicológicos hayan sido elitistas y muy especializados hasta fechas recientes, ha acentuado todavía más el retraso y el lento avance producido en la musicología con respecto al resto de las ciencias sociales. La musicología feminista en la actualidad, no puede comprenderse sin la influencia del postmodernismo y los vínculos que alrededor de este se establecen. A pesar de que no existe una teoría postmoderna unificada, podemos considerar esta un pensamiento que proliferó aproximadamente en la década de los 80 , el cual critica ideas propias del periodo ilustrado tales como la razón, la identidad, el progreso, la objetividad.

Palabras clave: mujer, música, género, sociedad.

\section{ABSTRACT}

Women's history, has focused mainly on making visible what had been hidden for years, giving voice to that silence. Likewise, attention has been paid to the manifestations that the patriarchal culture ignored and did not reconsider. The trend up to the 80s of the last century XX in music, is based mainly on the collection and accumulation of data.

The fact that the incorporation of feminism into music has been considerably late, has consistently led to a lack of tradition, a lack of studies that reflect the large number of talented musicians who were marginalized at the time. The fact that musical studies have been very elitist and very specialized until the latest news has further accentuated the delay and the slow progress made in musicology with respect to the rest of the social sciences. 
Feminine musicology today cannot be understood without the influence of postmodernism and the ties that surround it. Although there is no unified postmodern theory, we can consider this a thought that proliferated in the 1980s, which criticizes the ideas of the period illustrated as reason, identity, progress, objectivity.

Keywords: woman, music, gender, society.

\section{Introducción}

La red de relaciones que constituye la música es muy compleja y significativa. Como seres humanos, somos seres sociales, y toda vida social (independientemente al género al que pertenezcamos) está impregnada de música desde el momento en que nacemos. La historia de las mujeres, se ha centrado fundamentalmente en hacer visible lo que se había ocultado durante años, dando voz a dicho silencio. Para ello, ha sido necesario poner el centro de nuestra atención en las manifestaciones que la cultura patriarcal ignoró y no reconsideró.

En España, el s. XX ha estado marcado por la guerra civil. Es importante tener en cuenta esta situación ya que está íntimamente relacionado con el mundo laboral y el acceso de la mujer a éste. Es evidente que el final de la dictadura de Franco en la década de los 70 favoreció las condiciones de las mujeres a la hora de acceder al mercado laboral. La incorporación de la mujer al mundo de la interpretación, composición y dirección orquestal musical ha seguido un ritmo lento. No obstante, vamos avanzando cada vez más en términos de igualdad de sexos. A pesar de que queda un largo camino por recorrer, debemos tener en consideración también todo lo que se ha recorrido y logrado.

Este texto analiza una de las prácticas culturales invisibilizadas a lo largo de la historia: las prácticas musicales desarrolladas por las mujeres. Podemos estructurarla en cuatro puntos centrales: ${ }^{1}$

1 Programa de doctorado Intervención social: género y juventud. Universidad Rovira i Virgili. Tutora Ma Inmaculada Pastor Gosál158 bez.

Dossiers Feministes, 21, 2016, 157-174 - ISSN: $1139-1219$ - DOI: http://dx.doi.org/10.6035/Dossiers.2016.21.10 


\section{La invisibilidad de las mujeres en la historia de la música. Dificultades que ex- plican una menor participación de la mujer en la práctica musical en el pasado}

La presencia de las mujeres en el ámbito musical no es reciente. Además, la situación de la mujer no es la misma en todos los periodos históricos. Aunque sí que es cierto que ha estado en la sombra durante siglos, debemos tener presente que en determinados periodos de la historia ha gozado de mayores privilegios. Por ejemplo, durante la civilización egipcia, griega e incluso en algunas cortes renacentistas y barrocas, las mujeres se han podido sentir integradas en el mundo musical. También en las sociedades no industrializadas, las mujeres participaron activamente en la creación musical. Conocer las circunstancias sociales, políticas y/o económicas de cada periodo, nos ayudará a comprender mejor nuestra historia, y la de aquellas mujeres que bien aportaron su granito de arena como compositoras, intérpretes, directoras y docentes.

Tanto el matrimonio como la maternidad fueron (y en gran parte todavía lo son en la actualidad) obstáculos de gran peso en las carreras musicales de mujeres nacidas en los $\mathrm{s}$. XIX y XX. Cuando una mujer se casaba o bien tenía hijos, se esperaba de ella que se dedicara única y exclusivamente a estas tareas. Es decir, al cuidado de su marido y educación de los niños. Por lo tanto, la mujer se quedaba «encerrada» en el ámbito privado y doméstico, sin poder abrirse al mundo y expresarse con libertad.

Durante siglos, se ha perdido (además de ignorado) una valiosa información para poder conocer la historia de las mujeres. Tal y como afirma Virginia Woolf «las mujeres no han tenido el protagonismo creativo que les corresponde». A todas aquellas mujeres que en su momento desafiaron la sociedad en la que se desarrollaron, poniendo de manifiesto su labor artística y mostrándola a los demás tenemos mucho que agradecerles. Gracias a estas pioneras (a quienes tanto les debemos), las mujeres del siglo XXI podemos desarrollar una labor artística.

A lo largo de centenares de años, la mujer no ha tenido a su alcance los medios necesarios ni la formación adecuada para desarrollarse en el mundo musical. Si miramos atrás en el tiempo, tanto en el Renacimiento como en el posterior periodo Clásico, sólo aquellas mujeres que pertenecían a familias nobles o a la aristocracia podían ejercer como músicos. Eso sí, en su casa. Ni mucho menos en la esfera pública. Ya en el periodo Romántico contamos un mayor número de mujeres documentado como por ejemplo Clara Wieck Schumann (mujer del pianista y compositor Robert Schumann); Alma Mahler (mujer de Gustave Mahler), etc. A pesar que no hay duda alguna del talento de estas mujeres, siempre quedaron en un segundo plano. A la sombra de sus esposos o hermanos (como fue el caso de Fanny Mendelssohn, 
hermana de Félix Mendelssohn). Todavía en el s. XIX, para que una mujer pudiese publicar sus propias composiciones tenía que hacerlo bajo un pseudónimo masculino.

Hasta bien entrado el siglo XX, la presencia de mujeres en el ámbito artístico no ha sido notoria. Los círculos intelectuales y culturales han estado a lo largo de la historia frecuentados por hombres y en éstos las mujeres se han viso excluidas.

\section{El sesgo de género en los estudios musicológicos. La necesidad de la pers- pectiva feminista}

La tendencia hasta los años 80 del pasado siglo XX en musicología, se ha basado fundamentalmente en la recogida y acumulación de datos. Varios autores, entre los cuales debe destacarse el conocido musicólogo Joseph Kerman, calificaron a todos los musicólogos norteamericanos de «positivistas». Kerman consideraba que la musicología hasta la fecha, se había centrado fundamentalmente en recoger y confeccionar listas de datos, análisis musicales... sin hacer una valoración y crítica, en el mismo sentido que lo hace la hermenéutica. ${ }^{2}$

La mayor parte de artículos y monografías publicadas hasta los años 80 del pasado siglo, por lo tanto, eran de corte tradicional. El hecho de reconocer la desubicación producida, debido a la ausencia de mujeres en nuestra cultura histórica, debe hacer imprescindible superar los antiguos métodos de comprensión de la historia, para poder ser capaces de recrear los espacios significativos que las mujeres desarrollaron y fueron inmediatamente silenciados.

El canon de obras clásicas, el cual excluye todas aquellas obras musicales que han sido compuestas por mujeres, es uno de los puntos fundamentales sobre los que se ha centrado la crítica feminista. No hay ninguna duda que ha habido, a lo largo de la historia, intérpretes y compositoras mujeres las cuales poseían un gran talento musical y simplemente por el hecho de ser mujeres se les impidió desarrollar esta actividad del modo que sí lo hicieron sus colegas masculinos. Todo ello además, parece sorprendente si tenemos en cuenta que el origen del término música, procede de «las musas» de la antigua Grecia, vocablo el cual es femenino.

A la mayor parte de las mujeres intérpretes y compositoras se les destinó al ámbito privado, es decir, a interpretar obras en su propio hogar y realizar también la labor de docentes (de piano fundamentalmente) también en el contexto doméstico.

2 Esta crítica de Kerman se recogió en su manual «Contemplating music» editado en 1986 por la Harvard UniversityPress. 
Si tenían la suerte de poder salir de sus países de origen y ofrecer al público giras de conciertos (situación que no era la más común), se veían obligadas a contratar una dama de compañía si querían conservar su reputación. Además, debían contratar criadas que se ocuparan de los trabajos domésticos durante su ausencia.

Más allá de la exclusión que han experimentado las mujeres, a lo largo de la historia, para desarrollar la práctica musical, cabe destacar el sesgo de género que ha caracterizado a los estudios musicológicos. El hecho que la incorporación del feminismo a la musicología haya sido considerablemente tardía, ha comportado consecuentemente (como ya he comentado) una falta de tradición, una carencia de estudios en los cuales se refleje el gran número de músicas con talento que fueron marginadas en su época. El musicólogo Juan Pablo González, no se equivoca al afirmar que la musicología es una de las ciencias más conservadoras. El hecho que los estudios musicológicos hayan sido elitistas y muy especializados hasta fechas recientes, ha acentuado todavía más el retraso y el lento avance producido en la musicología con respecto al resto de las ciencias sociales.

Es prácticamente imposible encontrar referencias bibliográficas que puedan encuadrarse bajo los epígrafes de «musicología feminista» en el periodo anterior a los años 90 del pasado siglo XX. Debemos destacar la importancia en este contexto de lo que la autora Celia Amorós denominó «Hermenéutica de la sospecha» (Amorós, 1991: 178), la cual se basa en cuestionar todos aquellos documentos o discursos históricos, que han estado influenciados por el patriarcado. Por ello, lo que trata de hacer la historia de la música en la actualidad es la construcción de una historia de la música incluyendo en ésta la vida y obras de mujeres, contra la Historia de la Música que ha llegado hasta nuestros días. No obstante, y a pesar de que en la actualidad contamos con una mayor bibliografía de mujeres que eran fantásticas intérpretes y compositoras musicales, es necesario no centrarse solamente en su biografía. Así pues, es de capital importancia partir de sus creaciones musicales. Es decir, describir cual es la forma, el fraseo, analizar la armonía de sus piezas...y no adecuarse tan solo a patrones masculinos.

Algunos de los principales temas en los cuales se ha interesado la musicología feminista son la relación entre el compositor o la compositora y su obra, la terminología de la teoría musical, la periodización histórica, y también el mencionado canon de obras clásicas.

Por su parte, la etnomusicología, ya desde el inicio de sus estudios e investigaciones, tuvo cierto interés por las prácticas musicales llevadas a cabo por mujeres en los más diversos lugares del planeta tierra. Los etnomusicólogos, no obstante, se vieron fascinados explicando cómo y de qué manera la mujer participaba (en mucho casos activamente) desde tiempos memoriales en celebraciones populares. Me gustaría destacar a la escritora Cecilia Bhöl de 
Faber (1796 - 1877), conocida por su seudónimo de Fernán Caballero, por la extraordinaria recolección de canciones folklóricas en muchas de las cuales la presencia femenina era latente.

No será posteriormente, hasta la década de los 80 , cuando volveremos a encontrar cierto interés por incluir a las mujeres. Pese a esto, la primera fase de la musicología feminista se centró en la búsqueda incesante de datos, olvidando otros aspectos tanto o más importantes a la hora de recoger información. En una segunda fase, se cuestionaron aspectos como el canon, juicios de valor, jerarquías de géneros, el papel de los intérpretes.

Sin duda alguna, la musicología feminista en la actualidad, no puede comprenderse sin la influencia del postmodernismo y los vínculos que alrededor de este se establecen. A pesar de que no existe una teoría postmoderna unificada, podemos considerar ésta un pensamiento que proliferó aproximadamente en la década de los 80 , el cual critica ideas propias del periodo ilustrado tales como la razón, la identidad, el progreso, la objetividad. Debemos admitir también, que el postmodernismo cuestiona la validez de algunos conceptos que son claves para el feminismo, así como también fundamentos de la musicología: el concepto de música, el canon, el concepto de obra de arte...

Los actuales Estudios de Género, a diferencia de los discursos académicos tradicionales, se caracterizan por realizarse mediante el uso de una metodología interdisciplinar. Es decir, el motor que los impulsa es un nuevo criterio de lectura de los diversos discursos de conocimiento que existen. Estos estudios rechazan la singularidad esencialista y optan por los plurales diferenciadores de aquellos que han sido olvidados/as a lo largo de la historia.

A nivel cronológico, los Estudios de Género establecen una estrecha relación con la Historia del Feminismo. En sus inicios, la historiografía feminista se centró fundamentalmente en describir la presencia de la mujer en la historia, pensándose que podría realizarse una «historia total» en cuanto la inclusión de ésta se hubiera realizado. En la actualidad, podemos afirmar que nos encontramos con una confrontación de interpretaciones y de historias locales, regionales, de la cultura, de la educación, etc. Mientras tanto, la historiografía feminista se va insertando en esta multiplicidad de visiones históricas. En este contexto de mayor libertad, se pretende renovar las orientaciones metodológicas, conceptualizar nuevos problemas y en general, que la historia sea interpretada bajo nuevos enfoques. A este respecto añade Xavier Gil «hoy en día tiene poco sentido hablar con carácter excluyente de Historia Política, Historia Social o Historia Cultural.

La historia del feminismo suele dividirse en tres periodos o también denominados olas:

1.- La Primera Ola abarca el periodo que va desde la mitad del siglo XIX hasta la mitad del pasado siglo XX. Es entonces cuando se empieza a desarrollar la Teoría Feminista. 
En este periodo sobretodo se lucha por la igualdad a nivel de derechos (consecución de sufragio universal; conseguir una situación de igualdad entre hombres y mujeres...). Debemos destacar las figuras de Simone de Beauvoir y Virginia Woolf.

2.- La Segunda Ola se desarrolla entre los años 60 y 80 del siglo XX. Se empieza a usar el vocablo "género» en lugar de «sexo» en asuntos relativos a procesos culturales y sociales. Se busca una reconstrucción de la categoría de mujer. Se considera que el constructo de mujer que se había mantenido hasta la fecha se alzaba bajo perspectivas androcéntricas y poco realistas ${ }^{3}$.

3.- La Tercera Ola surgirá en la última década del siglo XX. En este periodo inician propiamente los que en la actualidad conocemos como Estudios de Género. Sus aportaciones ofrecen una visión crítica y sus propuestas de intervención se apoyan en teorías y métodos variados. Este periodo no se centra tanto en las diferencias entre hombres y mujeres sino también en las diferencias entre mujeres. Se pretende conseguir que el género se utilice como un criterio de relectura de los fenómenos culturales que nos rodean en los cuales tanto hombres como mujeres son partícipes. Eso dará lugar a que se comiencen a debatir muchos temas entre diversos colectivos sociales como: mujeres lesbianas, mujeres de color, ancianas, prostitutas, trabajadoras, inmigrantes, etc.

Cuando nos referimos a la Educación Musical, no parece tan evidente que la clasificación de las tres olas esté tan clara. Quizás el motivo principal sea que este tipo de perspectiva ha llegado más tarde en dicho campo. La visión más común que encontramos para analizar el desarrollo de los Estudios de Género y música es la siguiente: Lamb, Dollow and Howe 2000).

- Presencia de influencias no reconocidas a nivel disciplinario: comienza a manifestarse en los años 80 . Irán publicándose estudios en los cuales empiezan a incluirse cuestiones relacionadas con los Estudios de Género.

- Investigación compensatoria: comienza a desarrollarse en los años 90 . Se publican varias investigaciones cuyo objetivo es recuperar el lugar negado en las actividades musicales (realizadas por mujeres) relacionadas con la Educación como por ejemplo la elección de instrumento musical, la preferencia de una determinada práctica instrumental o vocal, etc.

3 La Historia Política en la Edad Moderna, Hoy: Un Aire Minimalista, Congreso nacional A Historia a Debate. Santiago de Compostela 7-1 1.7.93. p.2. 
- Crítica de las corrientes academicistas tradicionales: se desarrolla también en los años 90. Se trata de la corriente propiamente denominada Estudios de Género. Su objetivo será doble: deconstruir las propuestas de Educación Musical atendiendo a la perspectiva de género y, por otra parte, la elaboración (por parte de investigadores/as) de propuestas de intervención desde la nueva perspectiva. Todo ello pretende que se consiga un desarrollo igualitario de las diferencias que definen a hombres y mujeres.

Los principales ámbitos musicales (y que a continuación desarrollaré) sobre los que se han realizado un mayor número de investigaciones en relación con los Estudios de Género son:

1.- La investigación compensatoria.

2.- La relectura histórica.

3.- La investigación sobre el proceso de enseñanza-aprendizaje.

4.- La asignación de roles de género y la construcción de identidades de forma equitativa.

1.- La investigación compensatoria tiene como objetivo «compensar» los vacíos generados desde la tradicional perspectiva androcéntrica. Aquí se incluyen los trabajos que han recuperado nombres de multitud de mujeres que hasta hoy desconocíamos o conocíamos bien poco. En la actualidad, la tendencia es incluir la Pedagogía Feminista dentro de la Pedagogía Tradicional. Uno de los primeros trabajos compensatorios dentro del ámbito educativo-musical fue el realizado por Roberta Lamb en la década de los 80 . También publicó varias de sus obras más representativas en la década de los 90 . Estas publicaciones han hecho posible que un gran número de mujeres compositoras se incluyan en las obras que forman parte de nuestra Historia de la Música. A partir de los años 90 se continuarán realizando publicaciones de esta índole, además de artículos relativos a la Historia de las Mujeres en la Música, los cuales incluyen biografías de compositoras, intérpretes...Información de suma importancia para poder elaborar una práctica docente compensatoria.

2.- Uno de los pilares fundamentales en los Estudios de Género es la deconstrucción del discurso androcéntrico. Para ello, será necesario que se pongan en práctica nuevos procedimientos metodológicos con el objetivo de poder realizar nuevas y más completas lecturas. En los últimos años, ha suscitado un gran interés la Historia de la Educación. Gracias a ello, autores como Livingston (1991) y Humphreys (1990) han hecho posible que se realicen historiografías más equitativas. Livingston hace un repaso a aquellas mujeres cuyas vidas puedan servir de modelo a aquellas niñas, chicas y/o mujeres interesadas en carreras musicales. Nombra a Mary Salter, Carrie Jacobs Bond, Eleanor Freer, Amy Beach, Mary Howe

164

Dossiers Feministes, 21, 2016, 157-174 - ISSN: $1139-1219$ - DOI: http://dx.doi.org/10.6035/Dossiers.2016.21.10 
entre otras compositoras que han vivido o nacido en el siglo XIX y a Ruth Crawford Seeger, Louise Talma, Marga Richter, Emma Lou Diemer, Nancy Van de vate y otras nacidas en el siglo XX.

3.- El docente, es una pieza clave en todo proceso de enseñanza-aprendizaje. Es por ello, que es necesario e imprescindible analizar cuáles son sus prácticas. El presente siglo XXI se ha comenzado a trabajar en una línea relacionada con la Pedagogía Emancipatoria. Ésta demanda a los/las docentes una implicaciones individual, es decir, que sean críticos/as tanto con los estilos de enseñanza que ellos/as mismos utilizan como los que estilos institucionales. Es muy común entre los profesores/as la tendencia de percibir la voz femenina más apta para el canto y facetas interpretativas y relacionar el sexo masculino con facetas creativas y/o otras actividades que relacionan música y tecnología. Es entonces necesario una revisión de éstos (entre otros) planteamientos y expectativas, haciendo que sea posible un acceso más equitativo, libre de prejuicios y que permita superar (o al menos facilitar) la tradición división de roles. Los libros de texto, material que utilizan la mayor parte de profesorado el día a día en las aulas, continua siendo una herramienta recurrente tanto en educación primaria, como secundaria y conservatorios. Es imprescindible que el manual de texto que se use se revise y actualice. Sin embargo, los libros que se continúan utilizando están sin actualizar y continúan perpetuando la situación androcéntrica. Koza, Morton y $O^{\prime} T o o l e$ (entre otras) son autoras que trabajan en este campo. Su conclusión es que los manuales que continuamos utilizando estereotipan la participación de las mujeres en la música. Tras escribir una disertación de música en el siglo XIX titulada Godey's Lady's Book, Koza ha publicado artículos relacionados con la igualdad de género e ilustraciones de los «chicos invisibles» en los coros escolares. Por su parte Patti O'Toole ha publicado artículos relacionados con las relaciones de poder que se establecen en las agrupaciones corales.

4.- Son muchos los trabajos de investigación centrados en la investigación sobre la asignación de roles y la construcción de identidades. Durante varios siglos la práctica de la enseñanza musical ha ido siendo una práctica fundamentalmente femenina. No obstante, los líderes en este sector son (y siguen siendo) los hombres. Como bien hemos comentado en apartados anteriores, las actividades que exigen liderazgo acostumbran a tener mayor presencia masculina. Así, mientras que las mujeres son mayoría dirigiendo corales o enseñando en una escuela, quienes dirigen grandes agrupaciones orquestales son los hombres. Las últimas tendencias de investigación de los Estudios de Género no sólo se centran en la mujer, sino que incluyen otros colectivos de mujeres e incuso de hombres. En este sentido me gustaría 
destacar los estudios de «hombres ausentes». Entre otras cosas, estos estudios pretenden dar una explicación a la tradicional ausencia del sexo masculino en determinadas facetas musicales, poniendo énfasis en cómo se desenvuelven éstos en determinados ámbitos musicales que han sido tradicionalmente femeninos. Los profesores de música deben enfatizar que el canto es una actividad «masculina». Los cantantes masculinos adultos necesitan ser introducidos como modelos a seguir. Grabaciones y fotografías de hombres en coros, también pueden ser utilizados para fomentar el interés masculino en el canto». Kenneth H. (1988).

La investigadora americana Koza (1993), ha realizado un interesante estudio acerca de la situación de los varones en el mundo coral. Observó que los hombres solían descartar el hecho de formar parte de una coral fundamentalmente debido a:

- La percepción de que cantar no es una actividad apropiada para el sexo masculino.

- Los programas de canto coral no atendían los intereses y preferencias masculinas.

- Los cambios (a veces traumáticos) que se producen en la voz.

Los chicos evitaban cantar porque percibían esta actividad poco (o nada) relacionada con sus futuros planes de carrera.

\section{El liderazgo femenino en la dirección orquestal}

Denominamos liderazgo femenino a la utilización de las características propias de las mujeres para ejercer el papel de líder y/o coordinadora en el interior de una organización.

Nuestra sociedad se transforma a diario y muy rápidamente va adaptándose a los nuevos cambios. En este proceso de cambio, la mujer va dejando atrás su rol secundario del mundo privado que las mantenía alejadas del mundo público. Así, la mujer del siglo XX y XXI ha ido incorporándose a la población económicamente activa, está mejorando su calidad de vida, se ha incorporado a la educación...en general está alcanzando un lugar de relevancia en la sociedad. No obstante, persisten todavía los mitos que fomentan la dicotomía femenino/masculino en torno a la actividad de liderazgo. Así, todavía hoy permanece la imagen de hombre arquetipo maestro/director (estereotipo líder - macho).

Como seres sociales que somos, nos organizamos. Toda organización implica una coordinación y organización social y en este contexto la figura de un «líder» es fundamental. El vocablo «líder» proviene de la lengua inglesa «to lead», es decir, guiar. Así entonces, en un grupo de personas (independientemente del sexo y del número de éstas) el líder es la persona que se encarga de guiar a las demás. Así entonces en las organizaciones encontraremos seres sociales que son líderes y otros que son subordinados. La presencia de líderes está en

166

Dossiers Feministes, 21, 2016, 157-174 - ISSN: $1139-1219$ - DOI: http://dx.doi.org/10.6035/Dossiers.2016.21.10 
muchos y muy variados ámbitos: en el político, en el deportivo, en el educativo, en el mundo empresarial...el ámbito musical no es una excepción. La organización de una orquesta es un claro ejemplo de ello. Podemos afirmar que una orquesta es una organización que está compuesta por varios músicos altamente cualificados que siguen las instrucciones de un coordinador y/o líder. En este caso el líder es el director/a. La presencia de mujeres ocupando la posición de líder, coordinadora y/o guía es más bien escasa e incluso inexistente en muchos ámbitos. Volviendo al ejemplo anterior, ha sido impensable durante cientos de años que la figura del director de una orquesta sea una mujer. Hasta tiempos recientes, el mundo de la música clásica ha estado dominado por el sexo masculino.

Denominamos liderazgo femenino a la utilización de las características propias de las mujeres para ejercer el papel de líder y/o coordinadora en el interior de una organización. Nuestra sociedad se transforma a diario y muy rápidamente va adaptándose a los nuevos cambios. En este proceso de cambio, la mujer va dejando atrás su rol secundario del mundo privado que las mantenía alejadas del mundo público. Así, la mujer del siglo XX y XXI ha ido incorporándose a la población económicamente activa, está mejorando su calidad de vida, se ha incorporado a la educación...en general está alcanzando un lugar de relevancia en la sociedad.

No obstante, persisten todavía los mitos que fomentan la dicotomía femenino/masculino en torno a la actividad de liderazgo. Así, todavía hoy permanece la imagen de hombre arquetipo maestro/director (estereotipo líder - macho). Otro mito que parece pervive es el que difunde que la mujer no ha desarrollado las capacidades necesarias para ocupar puestos de liderazgo. Expone la crítica musical McClary «la confusión sobre si la música corresponde a la mente o al cuerpo se intensifica cuando la oposición binaria fundamental entre masculino y femenino se proyecta sobre ella. En la muy importante medida en que la mente se define como masculina y el cuerpo como femenino en la cultura occidental, la música corre siempre el riesgo de que se la considere como un asunto completamente femenino, y uno de los medios de afirmar el control masculino del medio consiste en negar la misma posibilidad de la participación de las mujeres, porque ¿̇cómo puede ser femenino un asunto si se excluyen de él a las mujeres de carne y hueso?

Otro de los principales motivos por los cuales ha sido tan difícil que la mujer llegue a ocupar el cargo de directora de orquesta es el que se denomina «techo de cristal». Es decir, la barrera transparente que no permite a la mujer acceder a cargos directivos o coordinación por el simple hecho de ser mujer. El sexo femenino ha tenido (y continua haciéndolo) que realizar un intenso esfuerzo para poder superar una serie de barreras sociales y culturales. Además, es muy frecuente que las mujeres que ocupan altos cargos se encuentren solas de- 
bido a la carencia de redes de contacto. Creo que se debería completar este apartado con algunos datos sobre las pocas mujeres que hay en la dirección de orquestas y si has entrevistado alguna se podría incluir alguna cita sobre su experiencia. Esto lo podemos valorar.

\section{Iniciativas desarrolladas para garantizar la igualdad entre hombres y mu- jeres en la práctica musical}

Aunque en pleno siglo XXI las Administraciones han comenzado a tener en cuenta la situación en la que se encuentra la mujer artista, es necesario que se actúe de verdad, aportando la máxima ayuda posible y diversas soluciones a este problema social y cultural. La cultura, que está financiada con dinero público de todos los españoles y españolas, debe actuar también de acuerdo a unos objetivos que tengan sentido y pongan de manifiesto la igualdad de sexos en este sistema democrático. Realizar estadísticas y poder evaluar el proceso, es de suma importancia para saber si realmente se ha avanzado o no. Así también para poder analizar las decisiones que se han ido tomando a lo largo del tiempo. En resumen, se trata de una «recopilación» de los pasos seguidos y las medidas que se han adoptado para poder extraer unas conclusiones desde una mirada crítica. Las diferentes estructuras de oportunidad y poder bloquean el acceso a la mujer y avanzar en las posiciones de lideraje.

Los años posteriores a la aprobación de la citada Ley de lgualdad (3/2007) se observa una evolución positiva y de cambio a favor de las mujeres artistas. Fundamentalmente estos nuevos derechos que adquiere la mujer van a suponer un cambio importante en:

- La relación laboral entre los trabajadores y empresarios.

- La vida familiar (mejoría en la conciliación de la vida familiar y laboral).

- Mayor número de mujeres que se incorporan en el mercado de trabajo.

- Mejora de las condiciones laborales de aquellas mujeres que ya estaban dentro del mundo laboral.

Explicar brevemente la aplicación general de la Ley de lgualdad y específicamente el contenido que afecta al ámbito musical y su aplicación tb en el ámbito musical En opinión de diferentes expertas (CITAR) podemos afirmar que en nuestro país se han consolidado acciones positivas y de transversalidad de lgualdad. Además, se han incluido diversos informes de impacto de género en todos los Ministerios, en los proyectos de ley y en la definición de los Presupuestos del Estado. Por lo tanto, todas estas medidas que se han tomado, son en principio sinónimo de avance en términos de lgualdad. 
En las líneas marcadas por el Plan Estratégico de lgualdad de Oportunidades (20082011 ), la materia cultural se encuentra incluida en el Eje 6: "Conocimiento». Éste punto incluye su propio Plan Estratégico de lgualdad, el cual pretende que se cumplan los siguientes objetivos:

- Promover la cultura como canal impulsor de la igualdad.

- Impulsar la representación femenina en las instituciones públicas que desarrollen políticas culturales.

- Fomentar el estudio y la investigación del papel de la mujer en la cultura.

- Reaccionar contra las manifestaciones culturales ofensivas a la dignidad de la mujer.

- Fomentar la creación artística e intelectual de la mujer y difundir su obra de forma preferencial.

- Enriquecer y difundir el patrimonio cultural de autoría femenina.

- Fomentar el papel de la mujer empresaria en el mundo de la cultura.

- Facilitar la incorporación de la igualdad en las empresas y entidades de gestión Cultural.

A favor de la lgualdad de Género (dentro del ámbito que estamos comentando) deben destacarse las siguientes medidas que se han llevado a cabo desde el Ministerio de Cultura:

- Portal web Mujeres en la Cultura, creado en 2007 . Tiene un carácter informativo y se recogen los premios concedidos a mujeres, publicaciones $u$ actividades desarrolladas por el Ministerio relacionadas con cuestiones de género y las aportaciones de las mujeres a la cultura en todas sus disciplinas.

- Adecuación de estadísticas y extensión de estudios y recopilación de datos desagregados por sexo, e incorporación de indicadores género. del 8 de marzo.

- Programa de actividades anuales en todos los departamentos para la celebración

- Festival cultural Ellas Crean: una muestra de la cooperación interministerial para la promoción de las mujeres en la música, el cine, las artes y otras manifestaciones culturales.

- Colaboración con asociaciones de mujeres de diferentes sectores culturales. Se ha establecido una línea de trabajo con las asociaciones de mujeres en el ámbito de la cultura que no solo se traducen en subvenciones nominativas de apoyo a su labor, sino en iniciativas concretas que se han llevado a cabo conjuntamente.

- Aumento de las adquisiciones de obras realizadas por mujeres (ARCO, MNCARS).

- Hacer posible la publicación de colecciones desde una perspectiva de género: con- 
venio de colaboración entre el Ministerio de Cultura y la Universidad Complutense de Madrid -a través del Instituto de Investigaciones Feministas-, cuyo objetivo es el estudio de fondos museísticos desde la perspectiva de género, para la creación de itinerarios, estadísticas, etc., en el Museo Arqueológico Nacional, el Museo del Traje, Museo del Prado y MNCARS.

- Con ojos de mujer y Mujer, sociedad y cultura: publicación de boletines bibliográficos de carácter monográfico relacionados con las actividades de mujeres en los campos de la creación artística e intelectual.

- DONESenART, asociación valenciana cuyo objetivo es el de crear un espacio dinámico y vivo en el ámbito de la creación e investigación escénica. Está dirigido por mujeres con el fin de promocionar las obras artísticas creadas por éstas.

- Participación del Ministerio de Cultura en los informes europeos sobre género en cine, televisión y teatro coordinados por la Federación Internacional de Actores (FIA), y representación en los foros europeos de Marsella y Bruselas, realizando interesantes aportaciones al documento de buenas prácticas que se elaboró a raíz de sendos encuentros. Seria interesante explicar un poco más las iniciativas nombradas Asimismo, es necesario mencionar también la labor que lleva a cabo el Observatorio de lgualdad. Está gestionado por el Instituto de la mujer y fue creado para poder dar respuesta a la necesidad de que se estableciera una igualdad de oportunidades entre Mujeres y Hombres, mediante el Real Decreto 1686/2000, de 6 de octubre. No entraría en funcionamiento hasta el año 2001. Sus dos objetivos más importantes son: - Evaluar la situación de la mujer en diversas áreas (Empleo, Educación, Reparto de Responsabilidades, Poder y toma de decisiones, Salud, Exclusión social...). - Evaluar los efectos producidos por las políticas de igualdad puestas en marcha.

- La Fundación AdkinsChiti - Women in music: organización cultural italiana cuyo lema es la «lgualdad de oportunidades para las mujeres en las Artes y en la Música». Esta asociación, nació el año 1978 como movimiento cuyo objetivo fue la promoción y presentación de música compuesta y creada por mujeres de todo el mundo. Los principales objetivos de la fundación son:

- Promover y fomentar la investigación, la conservación y la difusión de los documentos y la música clásica, tradicional, popular y electrónica en cualquier tipo de soporte (siempre y cuando esta obra sea fruto de la creatividad femenina).

- Establecer, mantener y promover los contactos con las bibliotecas y centros de documentación de la música de todo el mundo.

- Organizar y participar en estudios históricos y musicológicos de investigación, reuniones, seminarios, publicaciones y otras iniciativas relacionadas que involucran todo tipo de tecnología, espectáculos públicos.

170

Dossiers Feministes, 21, 2016, 157-174 - ISSN: $1139-1219$ - DOI: http://dx.doi.org/10.6035/Dossiers.2016.21.10 
En una mirada al contexto internacional, es relevante mencionar la League of American Orchestras. Se fundó en 1942. A partir de los años 50, esta liga comienza a elaborar programas de formación. En 1999, se constituye la Academia de Liderazgo de la Orquesta, cuyo objetivo fundamental fue reconocer y fomentar la realización efectiva y el liderazgo en las profesiones que comporta la orquesta. Ello se realizó bajo el compromiso de reforzar los conocimientos del personal, posibilitar el desarrollo de los líderes y en general una mejora de las prácticas. Todos estos esfuerzos han permitido que los líderes artistas tengan los conocimientos necesarios para ocupar un puesto de esta índole y que tengan la capacidad de realizar las funciones musicales, artísticas y de liderazgo de un modo equilibrado. Esto ha servido también para mostrar que los puntos fuertes que todo ser humano tiene no varían por cuestiones de género, sino de individuo a individuo, del mismo modo que las necesidades que tiene cada orquesta, al estar formadas por individuos diferentes, también tendrán unas necesidades distintas.

En la actualidad, no podemos negar que está presente la dicotomía femenino - masculino en torno a la actividad de liderazgo, y consecuentemente a la de director/a de orquesta. Persiste también el mito de que la mujer no ha desarrollado las capacidades necesarias para ocupar puestos de líder. McClary añade al respecto «la división entre mente y cuerpo, que ha invadido durante siglos la cultura occidental, se muestra paradójicamente con la máxima fuerza en las actitudes ante la música: el más cerebral e inmaterial de los medios es, al mismo tiempo, el más capaz de comprometer al cuerpo. Esta confusión sobre si la música corresponde a la mente o al cuerpo se intensifica cuando la oposición binaria fundamental entre masculino y femenino se proyecta sobre ella. En la muy importante medida en que la mente se define como masculina y el cuerpo como femenino en la cultura occidental, la música corre siempre el riesgo de que se la considere como un asunto completamente femenino en la cultura occidental, la música corre siempre el riesgo de que se la considere como un asunto completamente femenino (o afeminado), y uno de los medios de afirmar el control masculino del medio consiste en negar la misma posibilidad de la participación de las mujeres, porque, ¿cómo puede ser femenino un asunto si se excluyen de él a las mujeres de carne y hueso?». ${ }^{4}$

\section{Conclusiones}

Los cambios sociales y consecuentemente de pensamiento, además del hecho que cada vez más se contemple la «igualdad de género» (igualdad entre sexos), ha producido

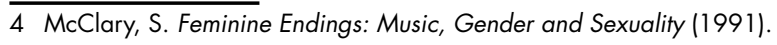


cambios importantes en la sociedad y en el modo de pensar de ésta. Es cierto también que las políticas de igualdad que se aplican no son las mismas en todos los países.

Las mujeres que se dedican a la música en la actualidad son testigos directos de que algunos de los estereotipos han sido (o están siendo) «desmontados» paulatinamente. De este modo poco a poco se está generando un gran número de mujeres-modelo donde verse reflejadas y con quien identificarse. No obstante, existe la convicción o creencia que en el siglo en que vivimos ya no hay discriminación por razón de sexo. Ello implicaría que hombres y mujeres tenemos los mismos derechos y estamos por tanto en condición de igualdad, pero en realidad no es así. Esto no quiere decir (como ya hemos comentado) que no haya habido un número suficiente de mujeres que se dedicaran a la música a lo largo de la historia, sino que muchas de ellas fueron marginadas socialmente, haciendo que la labor de éstas fuera «invisible».

Lo que está tratando de hacer la historia es la construcción de una historia de la música, (incluyendo en ésta la vida y obras de mujeres) contra la Historia de la Música que ha llegado hasta nuestros días. No obstante, y a pesar de que en la actualidad contamos con una mayor bibliografía de mujeres que eran fantásticas intérpretes y compositoras musicales, es necesario no centrarse solamente en su biografía. Así pues, es de capital importancia partir de sus creaciones musicales. Es decir, describir cual es la forma, el fraseo, analizar la armonía de sus piezas...y no adecuarse tan solo a patrones masculinos.

No sería del todo cierto atribuir la creación de ciertos estereotipos a las dificultades a las que se han enfrentado las mujeres compositoras y directoras de orquesta, pero no debemos olvidar que tales prejuicios existieron y que debemos continuar luchando para que no sigan existiendo estas diferencias de género a pesar del camino que se ha logrado recorrer.

La cultura de una sociedad, en este caso la Española, es el espejo en el que la sociedad de mira a sí misma. Por ello, todas esas mujeres creadoras que busquen modelos de referencia se darán cuenta rápidamente de esta carencia y falta de presencia. Esta situación, no hace más que perpetuar estereotipos, hábitos y actitudes y no igualitarias.

Teniendo en cuenta cuál es la situación en la que se encuentra la mujer, son necesarias medidas e impulsos para renovar y desechar viejos estereotipos generando una nueva atmosfera renovada para las generaciones futuras facilitando de este modo el camino (tan poco transitado) a aquellas mujeres que elijan el mundo de la dirección orquestal.

Además de las discriminaciones a nivel laboral y el denominado «techo de cristal» (íntimamente vinculado con labores como la maternidad, las tareas domésticas, la conciliación de la vida laboral y familiar...), a las mujeres que desarrollan su carrera en el ámbito artístico les falta referentes femeninos a los cuales apoyarse. Aunque el sexo masculino ha 
asimilado progresivamente el hecho de compartir las tareas del hogar durante el último cuarto de siglo, la mujer continúa asumiendo la carga principal. Además, las mujeres que forman una familia tienen más restricciones en viajar y reubicarse que los hombres en una situación similar. La sociedad todavía no es ve con buenos ojos el hecho que una mujer por cuestiones de trabajo tenga que ausentarse unos días, semanas o meses mientras que esta situación sí es aceptada y/o asimilada (al menos de mejor modo) cuando lo hace un hombre.

Las mujeres están presentes en todas las carreras universitarias que se ofrecen en nuestro país. No puede cuestionar su capacidad para ejercer las actividades profesionales en los diferentes ámbitos (ni mucho menos en la composición y dirección orquestal). Así entonces, continuemos luchando por una igualdad de derechos que esperamos algún día pueda alcanzarse plenamente.

\section{Bibliografia}

AdkINS ChITI, Patricia (1995): Las mujeres en la música: Madrid: Alianza Música.

AMORÓs, Andrés (1974): Subliteraturas. Barcelona: Ariel.

BOURDIEU, Pierre (1998): La dominación masculina. Barcelona: Anagrama.

Bowman, Wayne D. (1998): Philosophical Perspectives on Music. Orxford: Oxford University Press.

BuRKE, Peter (1993): Obertura: la nueva historia, su pasado y su future. Madrid: Alianza Musical.

Gordon, Linda (1977): Woman's Body, Woman's Right. London: Penguin Books.

GreEN, Lucy (1977): Music, Gender, Education. Cambridge: Cambridge University Press.

GreEN, Lucy (201 1): Learning, Teaching and Musical Identity: Voices Across Cultures. Bloomington: Indiana University Press.

HUMPHEYS, J.T. (1991): Thaddeus Bolton and the first dissertation in music education. Journal of Reserarch in Music Education, 38, 138-148.

KenNeth H. Phillips (1988): Choral Music Comes of Age. Music Educators journal 75, no. 4.

LAMB, Roberta (2000): «Feminism, Feminism Research, and Gender Research in Music Education. A Selective Review».

LIVINGSton, Carolyn (1991): Characteristics of American Women Composers: Implications for Music Education.

MARTí, Josep (2001): La música como generadora de realidades sociales. Barcelona: Deriva Editorial. 
Mcclary, Susan (1991): Feminine Endings: Music, Gender, and Sexuality.

PIÑERO GIL, Carmen (2009): Arte y Mujer. Madrid: Horas y horas editorial.

Scort, Joan Wallach (1991): Gender and the Politics of History. Nueva York: Columbia Universitu Press.

Recibido el 1 de febrero de 2016 Aceptado el 5 de marzo de 2016 BIBLID [1139-1219 (2016) 21: 157-174 